\title{
THE FACTORS INFLUENCING THE MATHEMATICS EXAM SUCCESS RATE IN THE STUDY PROGRAMMES TAUGHT AT THE COLLEGE OF POLYTECHNICS JIHLAVA (2006-2015)
}

Martina Zámková1 ${ }^{\bowtie}$, Martin Prokop², Radek Stolín ${ }^{3}$

${ }^{1 凶}$ Department of Mathematics, College of Polytechnics, Tolstého 16, Jihlava, 586 01, Czech Republic, +420 608 119079 , martina.zamkova@vspj.cz, martina.zamkova@centrum.cz

${ }^{2}$ Department of Mathematics, College of Polytechnics, Czech Republic

${ }^{3}$ Department of Mathematics, College of Polytechnics, Czech Republic

\section{Highlights}

- $\quad$ At our school the exam success rate in the course Mathematics 1 had been steadily decreasing

- Decreasing trend was observed in all of the offered study programmes

- Female students and students enrolled in the economic programmes tend to achieve better results

\section{Abstract}

This paper addresses the exam success rates in Mathematics 1 at the College of Polytechnics in Jihlava (CPJ). Primary data taken from the school information system cover the years 2006-2015. We carried out a success rate analysis based on several criteria (form of study, the reason for termination of studies, gender). We observed the dependence of the success rate on the aforementioned criteria and time. Plus a detailed analysis of the success rate with respect to the study programme was conducted. The contingency tables analysis and correspondence analysis were used to assess the dependencies. The research showed that the success rate in Mathematics 1 has been decreasing over the course of the monitored period of time. The success rate of full-time students is higher compared to the part-time students. Women have higher success rate than men. The respective study programmes showed equivalent results. Technical study programmes show lower success rate in mathematics. The research furthermore implies that mathematics may not always be the cause of a complete termination of studies. To reverse the trend of the growing failure rate we introduced an entrance test of high school basic mathematics followed by a course for those who fail at this test. As a part of our currently running project, our school have been innovating the e-learning modules and working on the textbooks for Seminar in Mathematics that may be completed in a form of an intensive summer or winter school in mathematics. This project's objective is an overall improvement of students' mathematical knowledge and skills.

\section{Keywords}

College of Polytechnics Jihlava, mathematics, students' knowledge, success rate

Zámková M., Prokop M., Stolín R. (2016) “The Factors Influencing The Mathematics Exam Success Rate in The Study Programmes Taught at The College of Polytechnics Jihlava (2006-2015)", Journal on Efficiency and Responsibility in Education and Science, Vol. 9, No. 3, pp. 52-59, online ISSN 1803-1617, printed ISSN 2336-2375, doi: 10.7160/eriesj.2016.090301.

\section{Introduction}

This article is an extended version of the paper presented on the 13th International Conference on Efficiency and Responsibility in Education (ERIE 2016) (Zámková, Prokop and Stolín 2016).

It is often said nowadays that the level of mathematical knowledge is decreasing. The objective of our research was, therefore, to assess the development of success rates in Mathematics 1 at the College of Polytechnics in Jihlava over the past 9 academic years. A detailed success rate analysis based on several criteria (study programme, form of study, the reason for termination of studies, gender) was carried out. The success rate of students in mathematics during the monitored period of time was evaluated with regard to the criteria. We used contingency tables analysis and Pearson's test of independence to test the dependency of the success rate on the aforementioned criteria and time. Row relative frequency and the graphic output of correspondence analysis (correspondence maps) were used to test the character of dependence.

A paper by Zámková and Blašková (2014) focused on similar issues. The paper's objective was to assess the Mathematics-1 exam success rate at the Faculty of Business and Economics of Mendel University in Brno. Another article (Fonteyne et al, 2015) assesses the impact of mathematical knowledge and skills on Ghent University students' success rate in a statistics course. Similarly Kučera, Svatošová, and Pelikán (2015) analysed the relationship between the admissions mathematics test results and the success rate in Mathematics, and Mathematical Methods in Economics.

A publication by Sonnert, Sadler, and Bressoud (2015) deals with the students' attitude toward mathematics in relation to the introductory calculus course and other relevant influential factors. The research shows that a positive attitude is strongly related to professors who offer clarity in presentation and answering questions, useful homework, fair exams, and help outside of class. The positive impact of technologies, such as graphing calculators, was not confirmed. The same applies to the usage of modern pedagogical methods. Majovská and Friedrich (2014) from the Technical University of Ostrava proved that the usage of simple study materials and (contrary to the findings of the previously mentioned paper) modern technologies improved students' success rate and their attitude towards mathematics.

The impact of the decreasing quality of high school mathematical education on university success rates in mathematics was addressed by Kučera, Jindrová, and Vydrová (2013). Universities are accepting less talented students due to the fact that there are fewer eligible candidates. This is a result of decreased population. The authors examined the success rate on courses that require mathematical skills (statistics, operations research) via a questionnaire survey. The survey showed no link 
between the high school type and the success rate. Kouřilová and Bebčáková (2015) concluded that the mathematical knowledge of students coming from high schools is decreasing each year. They analysed the success rate in mathematics with respect to various factors (high school type, students' behaviour, and overall study results).

Uysal(2007) compared the success rate in mathematics at selected schools in Turkey. The link between entrance mathematics and English language exams was analysed by Doucek and Maryška (2015). A psychologically oriented paper (Simzar et al, 2015) focused on the association between students' motivation for mathematics and their test results. Ulrychová (2015) addressed the relationship between the knowledge of mathematical theory and the ability to solve exercises among the students of University of Economics. The results lead her to question what the ideal ratio of theory to practise is in mathematics courses at non-technical universities.

\section{Materials and Methods}

Primary data was taken from the College of Polytechnics information system. The categorical data include students' success rates in Mathematics 1 for the years 2006-2015 and relevant identification variables. Mathematics 1 is supposed to provide students with basic knowledge of mathematical analysis and linear algebra.

Contingency tables present an easy way of displaying relations among categorical data. Depending on the character of the data we then used applicable tests of independence. According to Rezanková (1997), for the case of a contingency table of the $r \mathrm{x}$ $c$ type ( $r$ is the number of rows, $c$ is the number of columns) we most often use the test statistic:

$$
\chi^{2}=\sum_{i} \sum_{j} \frac{\left(n_{i j}-e_{i j}\right)^{2}}{e_{i j}},
$$

where $e_{i j}$ is the expected frequency and $n_{i j}$ the observed frequency. We use the statistic $\chi^{2}$ in Pearson's chi-square test with asymptotically $\chi_{(r-1)(c-1)}^{2}$ distribution. The null hypothesis of the test assumes independence. For further details see Hindls (2003). The condition that maximum $20 \%$ of the expected frequencies are less than five must be met in order to use the Pearson's chi-square test, see Hendl (2006) and Agresti (1990). We use Fisher's exact test in other cases or we calculate the simulated $p$-value of $\chi^{2}$ statistic, see Anděl (2005).

Correspondence analysis that was used for this study is a multivariate statistical technique, which allows the display and summary of a set of data in two-dimensional graphic form. It is traditionally applied to contingency tables - correspondence analysis decomposes the chi-squared statistic associated with this table into orthogonal factors. The distance between single points is defined as a chi-squared distance. The distance between $i$ th and $i$ 'th row is given by the formula

$$
D\left(i, i^{\prime}\right)=\sqrt{\sum_{j=1}^{c} \frac{\left(r_{i j}-r_{i^{\prime} j}\right)^{2}}{c_{j}}},
$$

where $r_{i j}$ are the elements of row profiles matrix $\boldsymbol{R}$ and weights $c_{j}$ are corresponding to the elements of column loadings vector $c^{T}$, which is equal to mean column profile (centroid) of column profiles in multidimensional space. The distance between columns $j$ and $j^{\prime}$ is defined similarly. The aim of this analysis is to reduce the multidimensional space of row and column profiles and to save maximally original data information (Hebák at al., 2007). The total variance of the data matrix is measured by the inertia, (see, e.g., Greenacre, 1984), which resembles a chi-square statistic but is calculated based on relative observed and expected frequencies. Unistat and Statistica software was used for primary data processing.

\section{Results}

In the surveyed period of time there were more women $(60.8 \%)$ than men enrolled in the CPJ study programmes that include maths courses. The majority of students in 2006-2015 studied Finance and Management (FM) $(57.8 \%)$, followed by the Travel and Tourism (TT) programme $(24.4 \%)$. The lowest number of students enrolled in the technically oriented programmes of Computer Systems (CS) and Applied Computer Science (ACS) (approx. 9\%). These were mostly fulltime students $(70.9 \%)$. Row relative frequencies (see Tab. 1) show that women have higher success rates in Mathematics 1 than men $(47.7 \%$ to $35.5 \%$ ). The detected $p$-value is less than 0.001 , which implies strong statistical dependence. Tab. 2 shows that the success rate of full-time students is higher compared to the success rate of the part-time students $(47.7 \%$ and $31.3 \%)$. Again, the detected $p$-value is less than 0.001 , which implies strong statistical dependence. Hence it is clearly easier to study the demanding full-time course, since this form of study offers students more opportunities to practice solving exercises during seminars.

\begin{tabular}{|c|c|c|}
\hline Row relative frequencies & Succeeded & Failed \\
\hline Women & $47.65 \%$ & $52.35 \%$ \\
\hline Men & $35.48 \%$ & $64.52 \%$ \\
\hline
\end{tabular}

Tab. 1: Contingency table: Gender and success rate in Mathematics 1, 2006-2015

\begin{tabular}{|c|c|c|}
\hline Row relative frequencies & Succeeded & Failed \\
\hline Full-time & $47.65 \%$ & $52.35 \%$ \\
\hline Part-time & $31.27 \%$ & $68.73 \%$ \\
\hline
\end{tabular}

Tab. 2: Contingency table: Form of study and success rate in Mathematics 1, 2006-2015

Furthermore, row relative frequencies (see Tab. 3) show that the lowest success rate is in the technically oriented programmes (CS and ACS) - about 32\%. The success rate in the economic programmes (FM and TT) is higher (around 45\%). The observed $p$-value is less than 0.001, which implies strong statistical dependence between the success rate and field of study.

\begin{tabular}{|c|c|c|}
\hline Row relative frequencies & Succeeded & Failed \\
\hline Finance and Management & $44.99 \%$ & $55.01 \%$ \\
\hline Applied Computer Science & $32.15 \%$ & $67.85 \%$ \\
\hline Computer Systems & $32.24 \%$ & $67.76 \%$ \\
\hline Travel and Tourism & $45.70 \%$ & $54.30 \%$ \\
\hline
\end{tabular}

Tab. 3: Contingency table: Study programme and success rate in Mathematics 1, 2006-2015

Tab. 4 shows that those studying at the moment or those who passed the final state exam have significantly higher success rate in mathematics. Roughly $18 \%$ passed the mathematics exam after repeating the course once. Interestingly $20 \%$ of expelled students and $14 \%$ of drop-outs passed the mathematics exam, therefore mathematics was not the reason of their overall failure, $p$-value is less than 0.001 . 


\begin{tabular}{|c|c|c|}
\hline Row relative frequencies & Succeeded & Failed \\
\hline $\begin{array}{c}\text { Did not comply with internal regulations } \\
\text { / Expelled }\end{array}$ & $20.66 \%$ & $79.34 \%$ \\
\hline Studying at the moment & $70.96 \%$ & $29.04 \%$ \\
\hline Passed the final state exam / Graduated & $82.38 \%$ & $17.62 \%$ \\
\hline Dropping out of college / Drop-out & $13.90 \%$ & $86.10 \%$ \\
\hline
\end{tabular}

Tab. 4: Contingency table: The reason for termination of studies and the success rate in Mathematics 1, 2006-2015

\begin{tabular}{|c|c|c|}
\hline Row relative frequencies & Succeeded & Failed \\
\hline $\mathbf{2 0 0 6} / \mathbf{2 0 0 7}$ & $72.22 \%$ & $27.78 \%$ \\
\hline $\mathbf{2 0 0 7 / 2 0 0 8}$ & $58.47 \%$ & $41.53 \%$ \\
\hline $\mathbf{2 0 0 8} / \mathbf{2 0 0 9}$ & $41.51 \%$ & $58.49 \%$ \\
\hline $\mathbf{2 0 0 9} / \mathbf{2 0 1 0}$ & $46.60 \%$ & $53.40 \%$ \\
\hline $\mathbf{2 0 1 0} / \mathbf{2 0 1 1}$ & $42.84 \%$ & $57.16 \%$ \\
\hline $\mathbf{2 0 1 1 / 2 0 1 2}$ & $41.23 \%$ & $58.77 \%$ \\
\hline $\mathbf{2 0 1 2} / \mathbf{2 0 1 3}$ & $35.09 \%$ & $64.91 \%$ \\
\hline $\mathbf{2 0 1 3} / \mathbf{2 0 1 4}$ & $31.88 \%$ & $68.12 \%$ \\
\hline $\mathbf{2 0 1 4} / \mathbf{2 0 1 5}$ & $31.91 \%$ & $68.09 \%$ \\
\hline
\end{tabular}

Tab. 5: Students' success rate in Mathematics 1, 2006-2015

The frequency table (see Tab. 5) and the graphic output (see Fig. 1) show that the success rate has been continuously decreasing over the course of the monitored period. The initial values of the success rate $(70 \%)$ drop to $30 \%$. The largest decline occurred in 2008 and 2009. The observed $p$-value is less than 0.001 , which implies strong statistical dependence between the success rate and the monitored period.

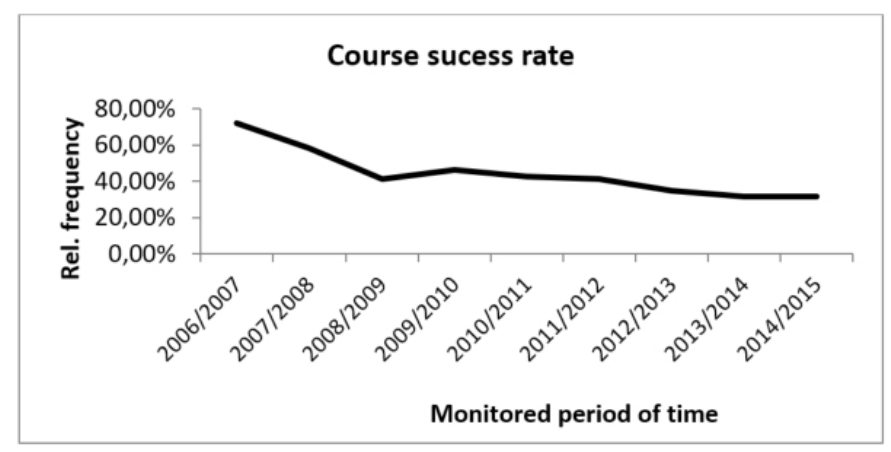

Fig. 1: Students success rate in Mathematics 1, 2006-2015

\begin{tabular}{|c|c|c|}
\hline Row relative frequencies & Succeeded & Failed \\
\hline $\mathbf{2 0 0 6 / 2 0 0 7}$ & $72.22 \%$ & $27.78 \%$ \\
\hline $\mathbf{2 0 0 7 / 2 0 0 8}$ & $58.47 \%$ & $41.53 \%$ \\
\hline $\mathbf{2 0 0 8} / \mathbf{2 0 0 9}$ & $39.59 \%$ & $60.41 \%$ \\
\hline $\mathbf{2 0 0 9 / 2 0 1 0}$ & $49.69 \%$ & $50.31 \%$ \\
\hline $\mathbf{2 0 1 0} / \mathbf{2 0 1 1}$ & $47.05 \%$ & $52.95 \%$ \\
\hline $\mathbf{2 0 1 1 / 2 0 1 2}$ & $49.35 \%$ & $50.65 \%$ \\
\hline $\mathbf{2 0 1 2} / \mathbf{2 0 1 3}$ & $39.96 \%$ & $60.04 \%$ \\
\hline $\mathbf{2 0 1 3} / \mathbf{2 0 1 4}$ & $35.69 \%$ & $64.31 \%$ \\
\hline $\mathbf{2 0 1 4} / \mathbf{2 0 1 5}$ & $34.97 \%$ & $65.03 \%$ \\
\hline
\end{tabular}

Tab. 6: Full-time students - Students' success rate in Mathematics 1, 2006-2015
Full-time students - course success rate

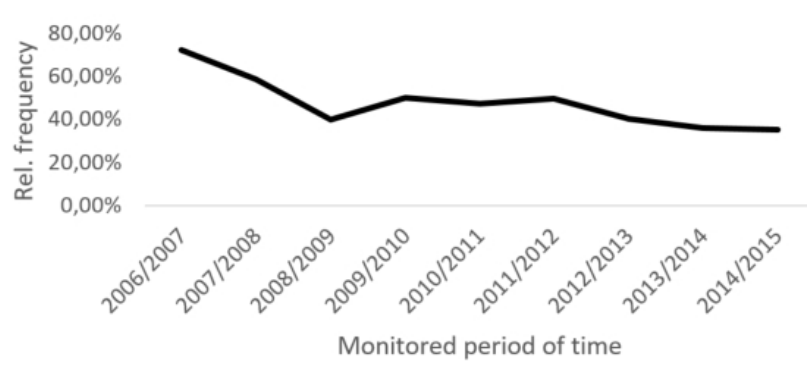

Fig. 2: Full-time students - Students' success rate in Mathematics 1, 2006-2015

Row relative frequencies (see Tab. 6) and the figure (see Fig. 2) show that at first, the success rate in mathematics of full-time students maintained values around $70 \%$. In 2008, the success rate dropped considerably to $50 \%$. Since 2012 , the success rate has been decreasing and it maintains the values of around $40 \%$. The detected $p$-value is less than 0.001 , which implies strong statistical dependence.

\begin{tabular}{|c|c|c|}
\hline Row relative frequencies & Succeeded & Failed \\
\hline $\mathbf{2 0 0 8} / \mathbf{2 0 0 9}$ & $53.98 \%$ & $46.02 \%$ \\
\hline $\mathbf{2 0 0 9 / 2 0 1 0}$ & $40.07 \%$ & $59.93 \%$ \\
\hline $\mathbf{2 0 1 0} / \mathbf{2 0 1 1}$ & $35.10 \%$ & $64.90 \%$ \\
\hline $\mathbf{2 0 1 1 / 2 0 1 2}$ & $28.93 \%$ & $71.07 \%$ \\
\hline $\mathbf{2 0 1 2} / \mathbf{2 0 1 3}$ & $25.89 \%$ & $74.11 \%$ \\
\hline $\mathbf{2 0 1 3} / \mathbf{2 0 1 4}$ & $24.78 \%$ & $75.22 \%$ \\
\hline $\mathbf{2 0 1 4} / \mathbf{2 0 1 5}$ & $28.71 \%$ & $71.29 \%$ \\
\hline
\end{tabular}

Tab. 7: Part-time students - Students' success rate in Mathematics 1, 2006-2015

\section{Part-time students - course success rate}

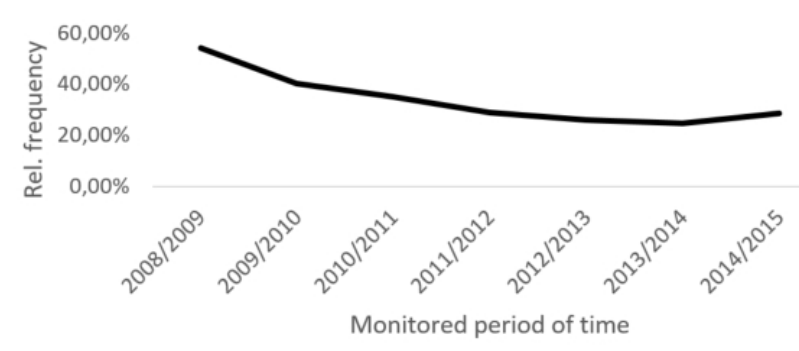

Fig. 3: Part-time students - Students' success rate in Mathematics 1, 2006-2015

As for the part-time form of study it is clear according to the the row relative frequencies (see Tab. 7) and the figure (see Fig. 3) that the success rate in mathematics of part-time students has been gradually decreasing from approx. $50 \%$ to about $25 \%$. However, in 2014, the success rate started to improve and the values almost reached $29 \%$. The detected $p$-value is less than 0.001 , which implies strong statistical dependence.

\begin{tabular}{|c|c|c|c|c|c|c|}
\hline $\begin{array}{c}\text { Row relative } \\
\text { frequencies }\end{array}$ & A & B & C & D & E & F \\
\hline $\begin{array}{c}\text { Finance and } \\
\text { Management }\end{array}$ & $3.21 \%$ & $3.65 \%$ & $9.39 \%$ & $7.58 \%$ & $16.45 \%$ & $59.72 \%$ \\
\hline $\begin{array}{c}\text { Applied } \\
\text { Computer } \\
\text { Science }\end{array}$ & $2.03 \%$ & $1.60 \%$ & $5.81 \%$ & $6.83 \%$ & $14.39 \%$ & $69.33 \%$ \\
\hline $\begin{array}{c}\text { Computer } \\
\text { Systems }\end{array}$ & $3.26 \%$ & $2.85 \%$ & $4.48 \%$ & $5.16 \%$ & $14.27 \%$ & $69.97 \%$ \\
\hline
\end{tabular}

Tab. 8: Final grades in Mathematics 1, 2006-2015 
In addition to that, we have assessed the results in the respective study programmes. Row relative frequencies (see Tab. 8) show that the most distinctive differences may be observed with regard to the $\mathrm{F}$ (failed) grades, where students of FM prove to have better success rate. This applies also to the A-E grades, only the difference is not that distinctive.

Plus, the observed $p$-value is less than 0.001 , which implies a strong statistical dependence between the final grades in Mathematics 1 and the study programme. The correspondence map (see Fig. 4) demonstrates that the success rate of FM students is placed approx. in the middle of the graphic output, between the grades. This means that the students' grades are evenly distributed on the scale A-F. The most frequent grade for the ACS and CS students is F (failed); the correspondence map shows that the $\mathrm{F}$ grade is placed near these two programmes. The biggest distance is separating the ACS students from A and $\mathrm{B}$ grades, which means that they are the ones who achieved good grades the least frequently.

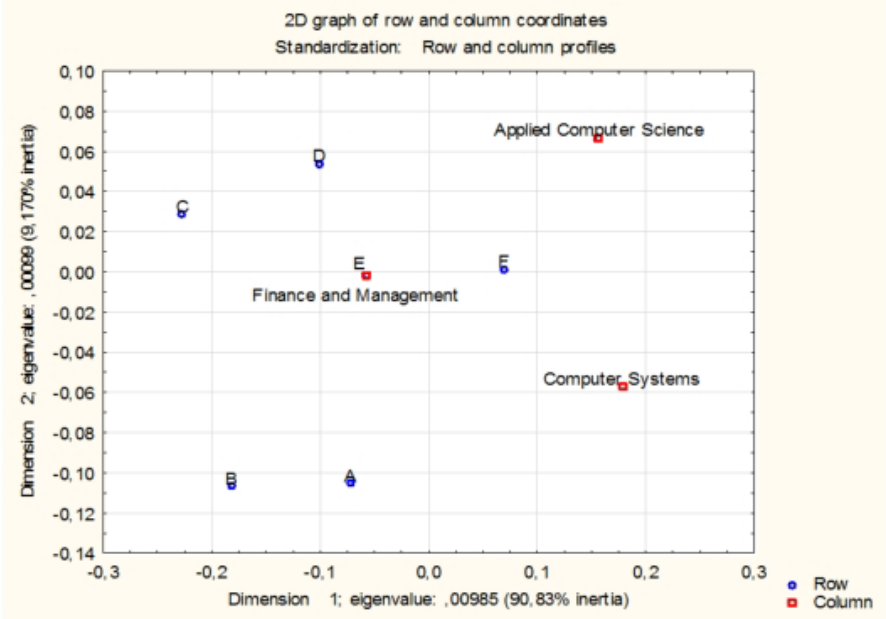

Fig. 4: Correspondence map: Study programme and final grades in Mathematics 1, 2006-2015

Row relative frequencies (see Tab. 9) show that full-time students achieved more A-E grades compared to the part-time students, who have most frequent $\mathrm{F}$ grades. The detected $p$-value is less than 0.001 , which implies strong statistical dependence.

\begin{tabular}{|c|c|c|c|c|c|c|}
\hline $\begin{array}{c}\text { Row relative } \\
\text { frequencies }\end{array}$ & A & B & C & D & E & F \\
\hline Full-time & $3.30 \%$ & $3.88 \%$ & $9.45 \%$ & $8.00 \%$ & $17.69 \%$ & $57.68 \%$ \\
\hline Part-time & $2.57 \%$ & $1.98 \%$ & $5.71 \%$ & $5.31 \%$ & $11.95 \%$ & $72.48 \%$ \\
\hline
\end{tabular}

Tab. 9: Contingency table: Form of study and final grades in Mathematics 1, 2006-2015

A strong statistical dependence ( $p$-value is less than 0.001) was confirmed with regard to gender and final grades in Mathematics 1. Row relative frequencies (see Tab. 10) show that women achieved more A-E grades compared to men, who have the majority of $\mathrm{F}$ grades.

\begin{tabular}{|c|c|c|c|c|c|c|}
\hline $\begin{array}{c}\text { Row relative } \\
\text { frequencies }\end{array}$ & A & B & C & D & E & F \\
\hline Women & $3.51 \%$ & $4.05 \%$ & $9.85 \%$ & $8.33 \%$ & $16.96 \%$ & $57.30 \%$ \\
\hline Men & $2.56 \%$ & $2.40 \%$ & $6.46 \%$ & $5.79 \%$ & $14.66 \%$ & $68.12 \%$ \\
\hline
\end{tabular}

Tab. 10: Contingency table: Gender and final grades in Mathematics 1, 2006-2015
The correspondence map (see Fig. 5) shows clearly a significant increase in the number of students graded with F, especially in the years 2012-2015. Conversely, the beginning of the monitored period of time saw students closer to the rest of the grades. Students from 2006 achieved the best grades.

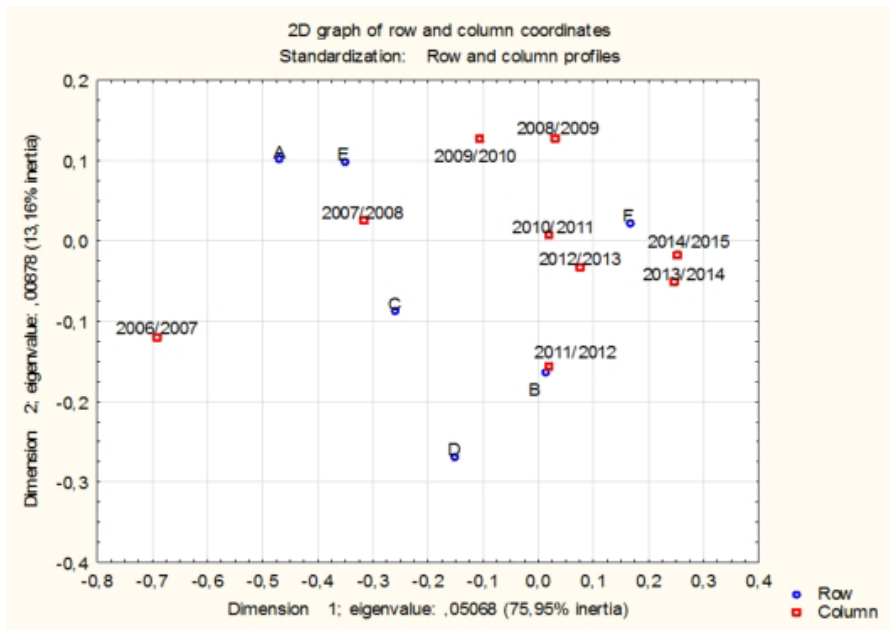

Fig. 5: Correspondence map: School years and final grades in Mathematics 1, 2006-2015

Furthermore we have conducted a detailed analysis focusing on the Finance and Management programme.

\begin{tabular}{|c|c|c|c|c|c|c|}
\hline $\begin{array}{c}\text { Row relative } \\
\text { frequencies }\end{array}$ & A & B & C & D & E & F \\
\hline Full-time & $3.46 \%$ & $4.48 \%$ & $10.96 \%$ & $8.58 \%$ & $18.83 \%$ & $53.69 \%$ \\
\hline Part-time & $2.74 \%$ & $2.11 \%$ & $6.47 \%$ & $5.69 \%$ & $12.02 \%$ & $70.98 \%$ \\
\hline
\end{tabular}

Tab. 11: Contingency table: Finance and Management - Form of study and final grades in Mathematics 1, 2006-2015

Row relative frequencies (see Tab. 11) show that the values of the full-time students are higher as for all of the grades except for the F grade. The detected $p$-value is less than 0.001 , which implies strong statistical dependence.

\begin{tabular}{|c|c|c|c|c|c|c|}
\hline $\begin{array}{c}\text { Row relative } \\
\text { frequencies }\end{array}$ & A & B & C & D & E & F \\
\hline Women & $3.58 \%$ & $4.18 \%$ & $10.18 \%$ & $8.42 \%$ & $17.48 \%$ & $56.16 \%$ \\
\hline Men & $2.36 \%$ & $2.44 \%$ & $7.56 \%$ & $5.61 \%$ & $14.07 \%$ & $67.97 \%$ \\
\hline
\end{tabular}

Tab. 12: Contingency table: Finance and Management - Gender and final grades in Mathematics 1, 2006-2015

Further row relative frequencies (see Tab. 12) indicate that the values of the female students are higher as for all of the grades except for the $\mathrm{F}$ grade. The detected $p$-value is less than 0.001 , which implies strong statistical dependence.

According to the table of the row relative frequencies (see Tab. 13) the values of the E grade especially (and partially of the $\mathrm{D}$ grade too) are decreasing in time, while the proportion of $\mathrm{F}$ grades is increasing. The detected $p$-value is less than 0.001 , which implies strong statistical dependence. 


\begin{tabular}{|c|c|c|c|c|c|c|}
\hline $\begin{array}{c}\text { Row relative } \\
\text { frequencies }\end{array}$ & A & B & C & D & E & F \\
\hline $\mathbf{2 0 0 6 / 2 0 0 7}$ & $8.67 \%$ & $5.10 \%$ & $21.94 \%$ & $14.29 \%$ & $35.20 \%$ & $14.80 \%$ \\
\hline $\mathbf{2 0 0 7 / 2 0 0 8}$ & $4.04 \%$ & $2.53 \%$ & $15.66 \%$ & $10.61 \%$ & $27.27 \%$ & $39.90 \%$ \\
\hline $\mathbf{2 0 0 8 / 2 0 0 9}$ & $3.77 \%$ & $2.69 \%$ & $6.46 \%$ & $3.59 \%$ & $17.06 \%$ & $66.43 \%$ \\
\hline $\mathbf{2 0 0 9 / 2 0 1 0}$ & $4.21 \%$ & $2.43 \%$ & $8.43 \%$ & $3.73 \%$ & $22.04 \%$ & $59.16 \%$ \\
\hline $\mathbf{2 0 1 0} / \mathbf{2 0 1 1}$ & $3.80 \%$ & $4.12 \%$ & $5.55 \%$ & $8.72 \%$ & $14.58 \%$ & $63.23 \%$ \\
\hline $\mathbf{2 0 1 1 / 2 0 1 2}$ & $1.08 \%$ & $3.42 \%$ & $9.35 \%$ & $10.43 \%$ & $14.75 \%$ & $60.97 \%$ \\
\hline $\mathbf{2 0 1 2 / 2 0 1 3}$ & $1.12 \%$ & $2.70 \%$ & $9.66 \%$ & $9.66 \%$ & $17.53 \%$ & $59.33 \%$ \\
\hline $\mathbf{2 0 1 3 / 2 0 1 4}$ & $2.43 \%$ & $6.09 \%$ & $10.55 \%$ & $6.90 \%$ & $7.71 \%$ & $66.33 \%$ \\
\hline $\mathbf{2 0 1 4} / \mathbf{2 0 1 5}$ & $3.11 \%$ & $4.40 \%$ & $10.10 \%$ & $6.99 \%$ & $6.99 \%$ & $68.39 \%$ \\
\hline
\end{tabular}

Tab. 13: Contingency table: Finance and Management - Monitored period of time and final grades in Mathematics 1, 2006-2015

Similarly we have conducted a detailed analysis focusing on the Applied Computer Science programme. This programme has been attended only by full-time students, see Tab. 14 .

\begin{tabular}{|c|c|c|c|c|c|c|}
\hline $\begin{array}{c}\text { Relative } \\
\text { frequencies }\end{array}$ & A & B & C & D & E & F \\
\hline Full-time & $2.03 \%$ & $1.60 \%$ & $5.81 \%$ & $6.83 \%$ & $14.39 \%$ & $69.33 \%$ \\
\hline
\end{tabular}

Tab. 14: Frequency table - Applied Computer Science - Form of study and final grades in Mathematics 1, 2006-2015

\begin{tabular}{|c|c|c|c|c|c|c|}
\hline $\begin{array}{c}\text { Row relative } \\
\text { frequencies }\end{array}$ & A & B & C & D & E & F \\
\hline Men & $2.28 \%$ & $1.63 \%$ & $6.36 \%$ & $6.69 \%$ & $15.82 \%$ & $67.21 \%$ \\
\hline Women & $0.00 \%$ & $1.33 \%$ & $1.33 \%$ & $8.00 \%$ & $2.67 \%$ & $86.67 \%$ \\
\hline
\end{tabular}

Tab. 15: Contingency table: Applied Computer Science - Gender and final grades in Mathematics 1, 2006-2015

The table of the row relative frequencies (see Tab. 15) shows that as for the Applied Computer Science, the success rate in Maths is not considerably dependent on the gender. The only more significant difference is apparent in the relative frequencies of the F grades - these were achieved more frequently by women. The detected $p$-value is less than 0.01 , which implies strong statistical dependence.

\begin{tabular}{|c|c|c|c|c|c|c|}
\hline $\begin{array}{c}\text { Row relative } \\
\text { frequencies }\end{array}$ & A & B & C & D & E & F \\
\hline $\mathbf{2 0 0 7 / 2 0 0 8}$ & $4.71 \%$ & $1.18 \%$ & $5.88 \%$ & $7.06 \%$ & $21.18 \%$ & $60.00 \%$ \\
\hline $\mathbf{2 0 0 8} / \mathbf{2 0 0 9}$ & $1.20 \%$ & $2.41 \%$ & $9.64 \%$ & $7.23 \%$ & $18.07 \%$ & $61.45 \%$ \\
\hline $\mathbf{2 0 0 9 / 2 0 1 0}$ & $2.33 \%$ & $3.49 \%$ & $16.28 \%$ & $8.14 \%$ & $13.95 \%$ & $55.81 \%$ \\
\hline $\mathbf{2 0 1 0} / \mathbf{2 0 1 1}$ & $4.30 \%$ & $0.00 \%$ & $5.38 \%$ & $6.45 \%$ & $23.66 \%$ & $60.22 \%$ \\
\hline $\mathbf{2 0 1 1 / 2 0 1 2}$ & $3.57 \%$ & $3.57 \%$ & $5.36 \%$ & $19.64 \%$ & $14.29 \%$ & $53.57 \%$ \\
\hline $\mathbf{2 0 1 2 / 2 0 1 3}$ & $1.41 \%$ & $1.41 \%$ & $1.41 \%$ & $2.82 \%$ & $5.63 \%$ & $87.32 \%$ \\
\hline $\mathbf{2 0 1 3} / \mathbf{2 0 1 4}$ & $0.00 \%$ & $1.63 \%$ & $2.44 \%$ & $2.44 \%$ & $8.13 \%$ & $85.37 \%$ \\
\hline $\mathbf{2 0 1 4} / \mathbf{2 0 1 5}$ & $0.00 \%$ & $0.00 \%$ & $1.10 \%$ & $6.59 \%$ & $10.99 \%$ & $81.32 \%$ \\
\hline
\end{tabular}

Tab. 16: Contingency table: Applied Computer Science-Monitored period of time and final grades in Mathematics 1, 2006-2015

An increasing trend may be observed mainly regarding the values of the F grades (see Tab. 16). The Pearson's chi-square test was not carried out due to the low values of the expected frequencies

Now let us take a look at the analysis of the programme called Computer Systems.

\begin{tabular}{|c|c|c|c|c|c|c|}
\hline $\begin{array}{c}\text { Row relative } \\
\text { frequencies }\end{array}$ & A & B & C & D & E & F \\
\hline Full-time & $4.28 \%$ & $3.83 \%$ & $6.08 \%$ & $6.31 \%$ & $15.99 \%$ & $63.51 \%$ \\
\hline Part-time & $1.71 \%$ & $1.37 \%$ & $2.05 \%$ & $3.42 \%$ & $11.64 \%$ & $79.79 \%$ \\
\hline
\end{tabular}

Tab. 17: Contingency table: Computer Systems - Form of study and final grades in Mathematics 1, 2006-2015

The full-time students tend to get better grades than F, (see Tab. 17). The detected $p$-value is less than 0.001 , which implies strong statistical dependence.

\begin{tabular}{|c|c|c|c|c|c|c|}
\hline $\begin{array}{c}\text { Row relative } \\
\text { frequencies }\end{array}$ & A & B & C & D & E & F \\
\hline Women & $4.88 \%$ & $0.00 \%$ & $2.44 \%$ & $2.44 \%$ & $7.32 \%$ & $82.93 \%$ \\
\hline Men & $3.17 \%$ & $3.02 \%$ & $4.60 \%$ & $5.32 \%$ & $14.68 \%$ & $69.21 \%$ \\
\hline
\end{tabular}

Tab. 18: Contingency table: Computer Systems - Gender and final grades in Mathematics 1, 2006-2015

The row relative frequencies (see Tab. 18) show that as for the best grade (A) the success rate of women is higher than the success rate of men, but the same applies to the $\mathrm{F}$ grade and the differences are not that significant. The Pearson's chi-square test was not carried out due to the low values of the expected frequencies

\begin{tabular}{|c|c|c|c|c|c|c|}
\hline $\begin{array}{c}\text { Row relative } \\
\text { frequencies }\end{array}$ & A & B & C & D & E & F \\
\hline $\mathbf{2 0 0 6 / 2 0 0 7}$ & $8.20 \%$ & $3.28 \%$ & $9.02 \%$ & $8.20 \%$ & $18.85 \%$ & $52.46 \%$ \\
\hline $\mathbf{2 0 0 7 / 2 0 0 8}$ & $3.39 \%$ & $6.78 \%$ & $8.47 \%$ & $0.00 \%$ & $23.73 \%$ & $57.63 \%$ \\
\hline $\mathbf{2 0 0 8 / 2 0 0 9}$ & $2.27 \%$ & $2.27 \%$ & $5.68 \%$ & $7.95 \%$ & $19.32 \%$ & $62.50 \%$ \\
\hline $\mathbf{2 0 0 9} / \mathbf{2 0 1 0}$ & $2.56 \%$ & $1.28 \%$ & $3.85 \%$ & $10.26 \%$ & $19.23 \%$ & $62.82 \%$ \\
\hline $\mathbf{2 0 1 0} / \mathbf{2 0 1 1}$ & $3.45 \%$ & $3.45 \%$ & $4.60 \%$ & $4.60 \%$ & $16.09 \%$ & $67.82 \%$ \\
\hline $\mathbf{2 0 1 1} / \mathbf{2 0 1 2}$ & $3.45 \%$ & $6.90 \%$ & $1.72 \%$ & $8.62 \%$ & $10.34 \%$ & $68.97 \%$ \\
\hline $\mathbf{2 0 1 2} / \mathbf{2 0 1 3}$ & $1.75 \%$ & $1.75 \%$ & $3.51 \%$ & $1.75 \%$ & $5.26 \%$ & $85.96 \%$ \\
\hline $\mathbf{2 0 1 3} / \mathbf{2 0 1 4}$ & $1.06 \%$ & $2.13 \%$ & $1.06 \%$ & $2.13 \%$ & $6.38 \%$ & $87.23 \%$ \\
\hline $\mathbf{2 0 1 4} / \mathbf{2 0 1 5}$ & $1.08 \%$ & $0.00 \%$ & $1.08 \%$ & $1.08 \%$ & $7.53 \%$ & $89.25 \%$ \\
\hline
\end{tabular}

Tab. 19: Contingency table: Computer Systems - monitored period of time and final grades in Mathematics 1, 2006-2015

The relative frequencies of the $\mathrm{F}$ grades are increasing with time. The table of the row relative frequencies (see Tab. 19) indicates that as for the A grades, there was a decrease in the success rate. This also applies partially to the $\mathrm{C}$ grades and (apart from the first year) to the E grades. The Pearson's chi-square test was not carried out due to the low values of the expected frequencies.

Travel and Tourism was the last programme that was analysed.

\begin{tabular}{|c|c|c|}
\hline $\begin{array}{c}\text { Row relative } \\
\text { frequencies }\end{array}$ & $\begin{array}{c}\text { course credit } \\
\text { granted }\end{array}$ & $\begin{array}{c}\text { course credit not } \\
\text { granted }\end{array}$ \\
\hline Full-time & $50.29 \%$ & $49.71 \%$ \\
\hline Part-time & $31.90 \%$ & $68.10 \%$ \\
\hline
\end{tabular}

Tab. 20: Contingency table: Travel and Tourism - Form of study and final grades in Mathematics 1, 2006-2015

The full-time TT students achieved better success rate $(50 \%$ compared to $32 \%$ ), (see Tab. 20). The detected p-value is less than 0.001, which implies strong statistical dependence. 


\begin{tabular}{|c|c|c|}
\hline $\begin{array}{c}\text { Row relative } \\
\text { frequencies }\end{array}$ & $\begin{array}{c}\text { course credit } \\
\text { granted }\end{array}$ & $\begin{array}{c}\text { course credit not } \\
\text { granted }\end{array}$ \\
\hline Women & $47.20 \%$ & $52.80 \%$ \\
\hline Men & $36.06 \%$ & $63.94 \%$ \\
\hline
\end{tabular}

Tab. 21: Contingency table: Travel and Tourism - Gender and final grades in Mathematics 1, 2006-2015

According to the row relative frequencies (see Tab. 21), female TT students achieved better success rate (47\% compared to 36 $\%)$ The detected $p$-value is less than 0.001 , which implies strong statistical dependence.

\begin{tabular}{|c|c|c|}
\hline $\begin{array}{c}\text { Row relative } \\
\text { frequencies }\end{array}$ & $\begin{array}{c}\text { course credit } \\
\text { granted }\end{array}$ & $\begin{array}{c}\text { course credit not } \\
\text { granted }\end{array}$ \\
\hline $\mathbf{2 0 0 7 / 2 0 0 8}$ & $81.58 \%$ & $18.42 \%$ \\
\hline $\mathbf{2 0 0 8 / 2 0 0 9}$ & $79.80 \%$ & $20.20 \%$ \\
\hline $\mathbf{2 0 0 9 / 2 0 1 0}$ & $69.23 \%$ & $30.77 \%$ \\
\hline $\mathbf{2 0 1 0 / 2 0 1 1}$ & $63.68 \%$ & $36.32 \%$ \\
\hline $\mathbf{2 0 1 1 / 2 0 1 2}$ & $44.02 \%$ & $55.98 \%$ \\
\hline $\mathbf{2 0 1 2 / 2 0 1 3}$ & $32.46 \%$ & $67.54 \%$ \\
\hline $\mathbf{2 0 1 3 / 2 0 1 4}$ & $35.25 \%$ & $64.75 \%$ \\
\hline $\mathbf{2 0 1 4 / 2 0 1 5}$ & $35.07 \%$ & $64.93 \%$ \\
\hline
\end{tabular}

Tab. 22: Contingency table: Travel and Tourism - Monitored period of time and final grades in Mathematics 1, 2006-2015

The TT programme saw the success rate gradually decrease from approx. $80 \%$ to about $35 \%$, where the decline stopped and these values have been maintained for roughly 3 years (see Tab. 22). The detected $p$-value is less than 0.001 , which implies strong statistical dependence.

\section{Discussion}

The article by Zámková and Blašková (2014) suggests that the most frequent grade obtained in mathematics at the Faculty of Business and Economics of Mendel University in Brno is F, and the same applies to our college.

Authors Kučera, Svatošová and Pelikán (2015) analysed the success rate in mathematics with respect to various factors. One of our objectives was to trace the factors influencing the students' success rate. Our findings show that gender, the form of study, and the study programme all have an impact on the success rate in Mathematics 1. While Uysal (2007) did not confirm the influence of gender, Kučera, Jindrová and Vydrová (2013) proved that there is a correspondence between gender and the success rate in maths. Our research implies strong statistical dependence between the success rate in mathematics and gender. A paper by Kučera, Jindrová and Vydrová (2013) suggests that the type of high school attended does not have any impact on achievement in mathematics. Similarly, Kourrilová and Bebčáková (2015) examine the impact of high school on the success rate in mathematics and they do find a certain dependence - the impact is therefore not positively confirmed.

As it was dealt by Ulrychová (2015) we are also looking at to what degree theory should be integrated into mathematical education, and our experience indicates that as much theory as is indispensably needed for solving the exercises should be taught.

In accordance with Sonnert, Sadler and Bressoud's publication (2015) students are more likely to accept traditional educational methods based on high-quality professors, rather than special technologies and modern practices. Modern methods are, in our opinion, more efficient in other fields of study, such as the humanities, social sciences etc. We share the idea of the paper by Simzar et al (2015) that the students' motivation matters. Our next research could focus on the comparison of results achieved in maths with those achieved in different courses (Doucek and Maryška, 2015). Should there be proof that good grades in mathematics tend to go hand in hand with good grades in other courses, students might see a verification of the fact that mathematics can be learned through diligent studying just as other subjects. Students are sometimes scared of mathematics beforehand and the findings of such analysis could be used to motivate them to study mathematics. There is an ambiguity of the research results: Majovská and Friedrich (2014) confirmed the positive impact of modern technologies while Sonnert, Sadler and Bressoud (2015) did not. In our opinion personality, educational methods, the motivational skills of individual teachers and the overall attitude of students is what matters most with regard to the improvement of students' results. The cause of good results acquired in the city of Ostrava (see Majovská and Friedrich, 2014) may be mainly the simplification and clarification of study materials. The College of Polytechnics is following the same path, including the restricted use of modern technologies where they prove to be effective. This concerns the creation and ongoing improvement of elearning modules for mathematics where everything is explained in a simple and clear way, plus the offer of a number of examples of exercises and opportunities to practice.

Based on our long-time experience it is evident that (when considering those students who actually want to study) there are two major factors causing their very high failure rate in mathematics nowadays. Factor number one is their insufficient knowledge and skills of secondary mathematics. Factor number two is students' unawareness of factor number one. For a long time we have been trying to eliminate factor number one, at least partially, by repetition of chosen parts of secondary mathematics (at the expense of higher mathematics) at the beginning of each semester. Currently, however, the lacking knowledge of secondary mathematics is so appalling that its repetition is not a matter of weeks, but at least months. Therefore we decided to focus on factor number two firstly. During the first seminar of Mathematics 1 the students are obliged to undergo an entrance test. The test verifies the fundamentals of secondary mathematics mastery. The students who pass the test can stay and continue with the course Mathematics 1 . The unsuccessful students may repeat this entrance test once during the next week and those who fail again may drop the course Mathematics 1 without losing their right to repeat this course in the future. Moreover, those who fail can attend a special compensatory course called Seminar in Mathematics to practice secondary mathematics. Its content includes simplification of algebraic expressions, absolute value of real number, solving linear and quadratic equations, including equations with absolute value, logarithm, solving logarithmical and exponential equations, elementary functions and their basic properties (drawing graphs included), summary of goniometric problems, goniometric formulas, simplification of goniometric expressions, goniometric equations, summary of trigonometric problems, vectors and vector operations, equations of line in different forms, conic section equations and their graphs, mutual position of a line and a conic section, summary of combinatorics, binomial theorem. The students that successfully pass the Seminar in Mathematics may afterwards enrol in the course Mathematics 1 without being obliged to pass the entrance test. The reason for this is that the aforementioned entrance test 
is equivalent to the final exam of the Seminar in Mathematics. Those who fail to pass even the Seminar in Mathematics have one other option - to participate in the intensive summer or winter school in mathematics, which takes place shortly after the exam period. Yet again, the final exam at the end of this intensive summer or winter school is a valid equivalent of the entrance test for the course Mathematics 1. By the way a similar approach is mentioned in Fonteyne et al (2015), where a basic mathematics entrance test targeting potentially struggling students and offering them alternatives is recommended.

The measures described in the last paragraph are part of an internal project aimed at improving the success rate in Mathematics 1. In this project new textbooks for Seminar in Mathematics are now being created and the e-learning module is being updated and it shall include new test and question banks matched with the topics taught.

\section{Conclusion}

The analysis showed that the success rate in Mathematics 1 has been decreasing in course of the monitored period of time. The success rate of full-time students is higher compared to the parttime students, it is thus clear that full-time studies bring better results in mathematics; the success rate of full-time students has been decreasing in the course of the monitored period of time from approx. $70 \%$ to under $40 \%$. While at the same time, the success rate of part-time students went down from about $50 \%$ to fewer than $30 \%$. This is obviously caused by the fact that part-time students are missing on the opportunity for a thorough practice with their professor. The research confirmed that women have higher success rate than men. Technically oriented programmes (ACS and CS) showed lower success rate in mathematics. Roughly $18 \%$ of the students passed the mathematics exam after repeating the course. This research also shows that mathematics may not always be the cause of complete termination of studies, about $26 \%$ of the students who failed their studies had different reasons (they dropped out or failed other courses). Detailed analysis of grades showed that $\mathrm{F}$ grades are more frequent among students enrolled in technically oriented programmes (compared to FM), among part-time students and among male students. The correspondence map of changes in time over a certain period of time shows clearly that there has been a significant increase in number of students graded with $\mathrm{F}$ in the past years, especially in years 2012-2015. The beginning of the monitored period of time saw students obtaining better grades more frequently. Students in the academic year of 2006/2007 achieved the best grades.

Thorough analysis of the respective programmes implies that as for the Finance and Management programme, all grades (except for the grade F) are obtained more frequently by the full-time students. The same dependency is implied as for the female FM students. Applied Computer Science was attended only by fulltime students. The success rate in ACS is not strongly dependent on gender. The only more significant difference is apparent in the relative frequencies of the $\mathrm{F}$ grades - these were achieved more frequently by women. As for Computer Systems, all grades (except for the grade F) are obtained more frequently by the full-time students. When it comes to the best grade (A) the success rate of women reached higher numbers, but this applies also to the $\mathrm{F}$ grade. In all of these programmes the frequency of $F$ grade occurrence is increasing in time. In the Travel and Tourism programme, the students are only granted credits when finishing the course successfully. Full-time students and female students of TT achieved better success rate. The success rate of these students gradually decreased from approx. $80 \%$ to about $35 \%$, where the decrease stopped and these values have been maintained for roughly 3 years.

The efficiency of suggested measures is to be reviewed and further development of the success rate in mathematics at the College of Polytechnics in Jihlava will continue to be observed in the framework of the ongoing internal project.

\section{Acknowledgement}

This research was supported by the College of Polytechnics, Jihlava, Czech Republic, under Grant no.1200/04/1614 "Complex of Pedagogically-Technical Innovations to Decrease the Failure Rate in Mathematics 1".

\section{References}

Agresti, A. (1990) Categorical Data Analysis, New York: John Wiley a Sons.

Anděl, J. (2005) Základy matematické statistiky, Praha: Matfyzpress.

Doucek, P. and Maryška, M. (2015) 'Are results of applicants excellent in mathematics and in English as well?' Proceedings of the 12th International Conference on Efficiency and Responsibility in Education (ERIE 2015), Prague, pp. 74-80.

Fonteyne, L. et al. (2015) 'Basic mathematics test predicts statistics achievement and overall first year academic success', European Journal of Psychology of Education, Vol. 30, No. 1, pp. 95-118.

Greenacre, M. J. (1984) Theory and Applications of Correspondence Analysis, London: Academic Press.

Hebák, P. et al. (2007) Vicerozměrné statistické metody 3, Praha: Informatorium.

Hendl, J. (2006) Přehled statistických metod: analýza a metaanalýza dat, Praha: Portal.

Hindls, R. (2003) Statistika pro economy, Praha: Professional Publishing.

Kučera, P., Jindrová, A. and Vydrová, H. V. (2013) 'Study success in mathematical subjects', Proceedings of the 10th International Conference on Efficiency and Responsibility in Education (ERIE 2013), Prague, pp. 333-340.

Kučera, P., Svatošová, L. and Pelikán, M. (2015) 'University study results as related to the admission exam results', Proceedings of the 12th International Conference on Efficiency and Responsibility in Education (ERIE 2015), Prague, pp. 318324.

Kouřilová, P. and Bebčáková, I. (2015) 'What happened to the students of applied mathematics?' Proceedings of the 12th International Conference on Efficiency and Responsibility in Education (ERIE 2015), Prague, pp. 273-279.

Majovská, R. and Friedrich, V. (2014) 'Responsibility for mathematical literacy', Proceedings of the 11th International Conference on Efficiency and Responsibility in Education (ERIE 2014), Prague, pp. 402-409.

Řezanková, H. (1997) Analýza kategoriálních dat pomocí SPSS, Praha: VŠE.

Simzar, R. M. et al. (2015) 'Raising the stakes: How students' motivation for mathematics associates with high- and lowstakes test achievement', Learning and Individual Differences, Vol. 39, pp. 49-63.

Sonnert, G., Sadler, P. M. and Bressoud, D. M. (2015) 'The impact of instructor pedagogy on college calculus students' 
attitude toward mathematics', International Journal of Mathematical Education in Science and Technology, Vol. 46, No. 3, pp. 370-387.

Ulrychová, E. (2015) 'Evaluation of mathematics tests relationship between theory and exercises', Proceedings of the 12th International Conference on Efficiency and Responsibility in Education (ERIE 2015), Prague, pp. 580-587.

Uysal, F. (2007) 'A comparison of the success of vocational school students in basic mathematics based upon their method of placement in university', Kuram ve Uygulamada Egitim Bilimleri, Vol. 7, No. 2, pp. 975-998.

Zámková, M. and Blašková, V. (2014) 'Mathematics-1 exam success rate at the Faculty of Business and Economics of Mendel University from 2008-2012', Proceedings of the 11th International Conference on Efficiency and Responsibility in Education (ERIE 2014), Prague, pp. 905-911.

Zámková, M., Prokop, M. and Stolín, R. (2016) 'Mathematics exam success rate at the College of Polytechnics Jihlava (20062015)', Proceedings of the 13th International Conference on Efficiency and Responsibility in Education (ERIE 2016), Prague, pp. 674-681. 